\title{
A continuous climate-vegetation classification for use in climate-biosphere studies
}

\author{
Victor Brovkin *, Andrei Ganopolski, Yuri Svirezhev \\ Potsdam Institute for Climate Impact Research, Postfach 601203 Telegrafenberg, 14412, Potsdam, Germany
}

Accepted 20 January 1997

\begin{abstract}
An interactive coupling of global climate models with models for the terrestrial vegetation requires a reduction of the number of vegetation classes in comparison with traditional bioclimatic classification. We suggest a continuous vegetation classification based on two main plant functional types: trees and grass. Correspondence between climate and these vegetation types on a global scale was analysed on the basis of state-of-the-art global climate and vegetation datasets. An empirical formula describing a fraction of trees as a function of climate (mean annual temperature and precipitation) was obtained. (C) 1997 Elsevier Science B.V.
\end{abstract}

Keywords: Vegetation classification; Plant functional types; Trees; Grass

\section{Introduction}

Climate and vegetation closely coincide on a global level (Walter, 1964, 1968; Odum, 1983). Due to this phenomenon, the correlation analysis of the spatial patterns of vegetation and climate has been a topic for biogeographical studies for a long time. This analysis results in the creation of climate-vegetation classifications: the correspondence between climate and vegetation has been expressed in quantitative terms (Köppen, 1936;

* Correspondind author. Tel: + 493312781159 ; fax: +49 331 2781204; e-mail: victor@pik-potsdam.de
Holdridge, 1947). The underlying assumption of these classifications is that vegetation exists in equilibrium with climate.

Climate-vegetation classification could be done by two principally different methods: a deterministic and probabilistic approach. In the case of a deterministic approach, one-to-one correspondence between climate and vegetation is suggested. It reflects the hypothesis that equilibrium distribution of vegetation is determined only by climate. The Holdridge Life Zone Classification (Holdridge, 1947) is the most well-known example of deterministic classification; this approach was useful for analysis of climate change consequences 
(see, e.g. Monserud and Leemans, 1992). Let us note that the Holdridge's classification was based on the observations of vegetation in the mountains, where changes among different vegetation types are very distinct. The advanced climate-vegetation classification has been proposed by (Prentice et al., 1992). In this model, called BIOME, an occurrence of plant functional types depends upon threshold values of five bioclimatic variables. (Henderson-Sellers and McGuffie, 1995) presented their own climatevegetation classification, in which a significant place in climate parametric space is assigned to agriculture crops.

Let us emphasise that deterministic climatevegetation classification is based not only on the quantitative or statistical analysis of data, but also on the author's choice of:

- which climate parameters are the most important ones for classification;

- the thresholds for separation of different vegetation types.

Because of scarcity of data for some geographic regions, these hypotheses are absolutely necessary to fill the gaps in the empirical knowledge. At the same time, these hypotheses could be criticised for their subjectivity.

The other classification method is the probabilistic approach: several vegetation types could co-exist at one place with different probability of their occurrence. This approach, known as the method of climate response surface (Bartlein et al., 1986), is based on advanced datasets of climate and vegetation data. Originally, this method was applied for relating the abundance of pollen taxa in contemporary surface samples to climate conditions. (Lenihan, 1993) applied this approach to contemporary distribution of vegetation based on the current maps showing dominance of different species in geographical space. The results demonstrate a good correspondence with the original maps.

The important point to underline is that the method of climate response surfaces has been applied before on a regional level. The availability of global, geographically explicit data sets of vegetation (Matthews, 1984; Olson and Watts, 1992) and climate (Leemans and Cramer, 1991) offers new opportunities for analysis of the correspondence between climate and vegetation on a global level. Based on these data, it is possible to design a continuous classification for global change studies.

\section{Methods}

An important assumption of many vegetation models designed for global change studies (Melillo et al., 1993; Ludeke et al., 1994) is that every geographical unit (grid cell) is homogeneous. So, there is only one vegetation type (ecosystem, biome) within the cell. The possibility of validating models on the basis of local data is an advantage of this approach. However, a multitude of vegetation types leads to complexities in application of such a model for the climate-biosphere studies. Indeed, interactive coupling of a terrestrial vegetation model with a climate model requires the transformation of vegetation characteristics into bioclimatic parameters such as surface albedo (summer and winter), roughness length, roots allocation among different soil layers, leaf area index, etc. The lack of empirical data and large variability of these parameters within one biome type lead to the fact that the sets of bioclimatic parameters differ significantly only for two major plant functional types-trees and grass, while few intermediate biomes (such as savannah) are characterised by intermediate values of these parameters (Dickinson et al., 1986). Moreover, trees and grass have a differing allocation function for carbon between active and structural phytomass as well as a different residence time of carbon in plant organs. These differences between trees and grass are the greatest among all plant functional types.

These arguments could justify (at least for the purposes of climate change studies) a substantial reduction of the number of plant functional types in comparison to that used in advanced terrestrial vegetation models. The climate models operate with very rough spatial resolution; typically it is about several hundreds kilometres. Discrete vegetation description implies instant 
Table 1

Parametrization of World Ecosystems classification (Olson and Watts, 1992)

\begin{tabular}{|c|c|c|c|}
\hline Category & Area, mln. $\mathrm{km}^{2}$ & Ecosystem complex & $f_{g}$ \\
\hline 21 & 5.4 & Main boreal coniferous forest & 1 \\
\hline 22 & 2.9 & Snowy non-boreal coniferous forest & 1 \\
\hline 23 & 1.6 & Coniferous/deciduous forest, snow persisting in winter & 1 \\
\hline 24 & 1.9 & Temperate broadleaf/coniferous forest: with deciduous and /or evergreen hardwood trees & 1 \\
\hline 25 & 0.8 & Snowy deciduous forest & 1 \\
\hline 26 & 0.8 & Temperate broadleaf forest & 1 \\
\hline 27 & 0.4 & Non-snowy coniferous forest & 1 \\
\hline 28 & 1.1 & Tropical montane complexes (tree and other) & 0.8 \\
\hline 29 & 6.0 & Tropical broadleaf seasonal forest & 1 \\
\hline 32 & 4.6 & Rain-green (drought-deciduous) (major forest and woodland) & 0.8 \\
\hline 33 & 4.1 & Tropical rainforest & 1 \\
\hline 40 & 3.9 & Cool grass/shrub, snowy in most years & 0.1 \\
\hline 41 & 17.2 & Mild/warm/hot grass/shrub & 0.1 \\
\hline 42 & 0.9 & Cold steppe/meadow \pm larch, scrub & 0.1 \\
\hline 43 & 6.6 & Savannah/grass, seasonal woods & 0.1 \\
\hline 46 & 0.9 & Mediterranean-type evergreen (mostly) broadleaved scrub and forest relics & 0.5 \\
\hline 47 & 2.5 & Dry or highland scrub, or open woodland & 0.3 \\
\hline 48 & 0.9 & Dry evergreen woodland or low forest & 0.3 \\
\hline 51 & 10.8 & Semidesert/desert & 0 \\
\hline 52 & 2.1 & Coolicold shrub semidesert/steppe & 0.1 \\
\hline 53 & 9.4 & Tundra (polar, alpine) & 0 \\
\hline 59 & 3.9 & Succulent and thorn woods or scrub is widespread & 0.5 \\
\hline 60 & 1.2 & Southern dry taiga & 1 \\
\hline 61 & 0.5 & Larch taiga with deciduous conifers & 1 \\
\hline 62 & 4.6 & Northern or maritime taiga/tundra & 0.5 \\
\hline 63 & 1.7 & Wooded tundra margin (or mountain scrub/meadow) & 0.2 \\
\hline
\end{tabular}

changes of biome types. Possible jumps in climatically significant surface parameters for the large areas inevitably affect the model sensitivity and could lead to underestimation or overestimation of the model sensitivity and strength of vegetation-climate feedbacks. This problem could be overcome by making the assumption that every grid cell is covered by a mixture of a few basic plant functional types, the ratio of these could continuously change under changing climate conditions. This idea, but with a fixed ratio of forest corresponding to the present climate conditions, was implemented in MPI climate model ECHAM (Claussen et al., 1994). Here we present an extension of this approach for changing climate conditions. Our aim is to design a continuous function describing well enough the regularities of the distribution of the trees fraction in climate space and to apply it in climate change study.

\subsection{Simplified vegetation classification: trees and grass}

In our approach, we suggest using only two vegetation types: trees and grass. Another aspect of the simplification is that the potential proportion of vegetation types is controlled by climate. Let $f_{g}$ be a fraction of trees, $g_{g}$-a fraction of grass for every land cell in a geographic space. These fractions are non-negative and their sum is equal to one:

$f_{g}+g_{g}=1$

Map of World Ecosystem Complexes (Olson and Watts, 1992) and Leemans and Cramer's Climate Dataset (Leemans and Cramer, 1991) were used for analysis of correspondence between climate and vegetation. The important point of the analysis was the prescribing of the trees fraction $f_{g}$ based on the Olson and Watts' classifica- 
tion. For forest types of this classification a fraction $f_{g}$ was determined as 1 (see Table 1). For tundra $f_{g}$ was taken as 0 . For more complex cases a fraction of trees was estimated in accordance with their description. For example, northern or maritime taiga and tundra is suggested to be half trees and half grass; for savannah the trees fraction was prescribed as 0.1 . It was difficult to estimate $f_{g}$ for ecosystems in agricultural areas, so they were omitted from the following processing. Wetlands and marshes as well as ice and sand deserts are also not analysed. All together, the areas excluded from analysis consist of about $30 \%$ of the terrestrial Earth. A list of the prescribed trees fraction for each of 26 analysed ecosystem complexes is presented in Table 1.

Our method is a transformation of a continuous characteristic of vegetation (the trees fraction) from a 2-dimensional geographical space (where every cell has latitude $x$ and longitude $y$ ) into a 2-dimensional space of climate parameters. For easy application for global change studies, only two climate predictors have been taken into account: $T$-mean annual temperature $\left({ }^{\circ} \mathrm{C}\right)$ and $P$ mean annual precipitation ( $\mathrm{mm} /$ year). An aim of the analysis is to find regularities of distribution of the trees fraction in this climate space.

The climate space was subdivided into grids with a temperature step of $\Delta T=1^{\circ} \mathrm{C}$ and a precipitation step of $\Delta P=50 \mathrm{~mm} /$ year.

For every climate cell an average trees fraction $f_{c}$ was calculated as the following:

$f_{c}(T, P)=\frac{\int_{\Omega} \int a(x, y) \mu(x, y, T, P) f_{g}(x, y) \mathrm{d} x \mathrm{~d} y}{\int_{\Omega} \int_{a} a(x, y) \mu(x, y, T, P) \mathrm{d} x \mathrm{~d} y}$

where $a(x, y)$ is an area of a grid cell with $x, y$ coordinates in geographical space, $\Omega$ is the land surface, $\mu$ is the following function:

$$
\mu(x, y, T, P)=\left\{\begin{array}{l}
1, \text { if } T<\hat{T}(x, y)<T+\Delta T \text { and } \\
P \leq \hat{P}(x, y)<P+\Delta P \\
0, \text { otherwise }
\end{array}\right.
$$

$\hat{\mathrm{T}}(x, y)$ and $\hat{\mathrm{P}}(x, y)$ are temperature and precipitation, correspondingly, in grid cell with $x, y$ coordinates in geographical space.

In order to produce a more understandable image of the Earth in climate space, climate cells representing land areas smaller than $10000 \mathrm{~km}^{2}$ were omitted from the following analysis.

\subsection{Distribution of the trees fraction in a climate space}

Fig. 1a illustrates results of the transformation of geographical space into climate space. The first large pattern with a fraction of trees of above 0.75 occurs within the temperature interval from $-8^{\circ} \mathrm{C}$ up to $8^{\circ} \mathrm{C}$. It corresponds mainly to zones of boreal and subboreal forests in the Northern hemisphere. The second pattern showing a high trees ratio corresponds to the zone of tropical forests (temperature above $20^{\circ} \mathrm{C}$ ). Most of the geographical cells from temperate and subtropical zones were omitted from the analysis due to the vast anthropogenic activity in these zones. Therefore the absence of any large forest pattern in climate space between 8 and $20^{\circ} \mathrm{C}$ could be not a consequence of natural regularity, but a result of land use changes over large areas (e.g. in Europe, North America and China) covered previously by temperate deciduous forests.

The distribution of the trees fraction $f_{c}$ in Fig. 1 a demonstrates the following regularities: firstly, for a fixed temperature, $f_{c}$ increases with increase of precipitation; secondly, for fixed precipitation, $f_{c}$ decreases with increase of temperature. In other words, trees prefer to grow in places with sufficient water supply. This qualitative rule was consistent with results of (Lieth, 1975) analysis of the distribution of main vegetation types in the same climate parametric space. Another regularity is $f$ c decreases down to zero with decrease of temperature below some threshold (about $-10^{\circ} \mathrm{C}$ ). For temperature below the critical threshold of about $-15^{\circ} \mathrm{C}$, the trees fraction is near zero. This threshold could be explained by the soil permafrost phenomenon, which is one of the main restrictions on forest expansion in the vast areas of the tundra zone in Northern Eurasia and Northern America. 


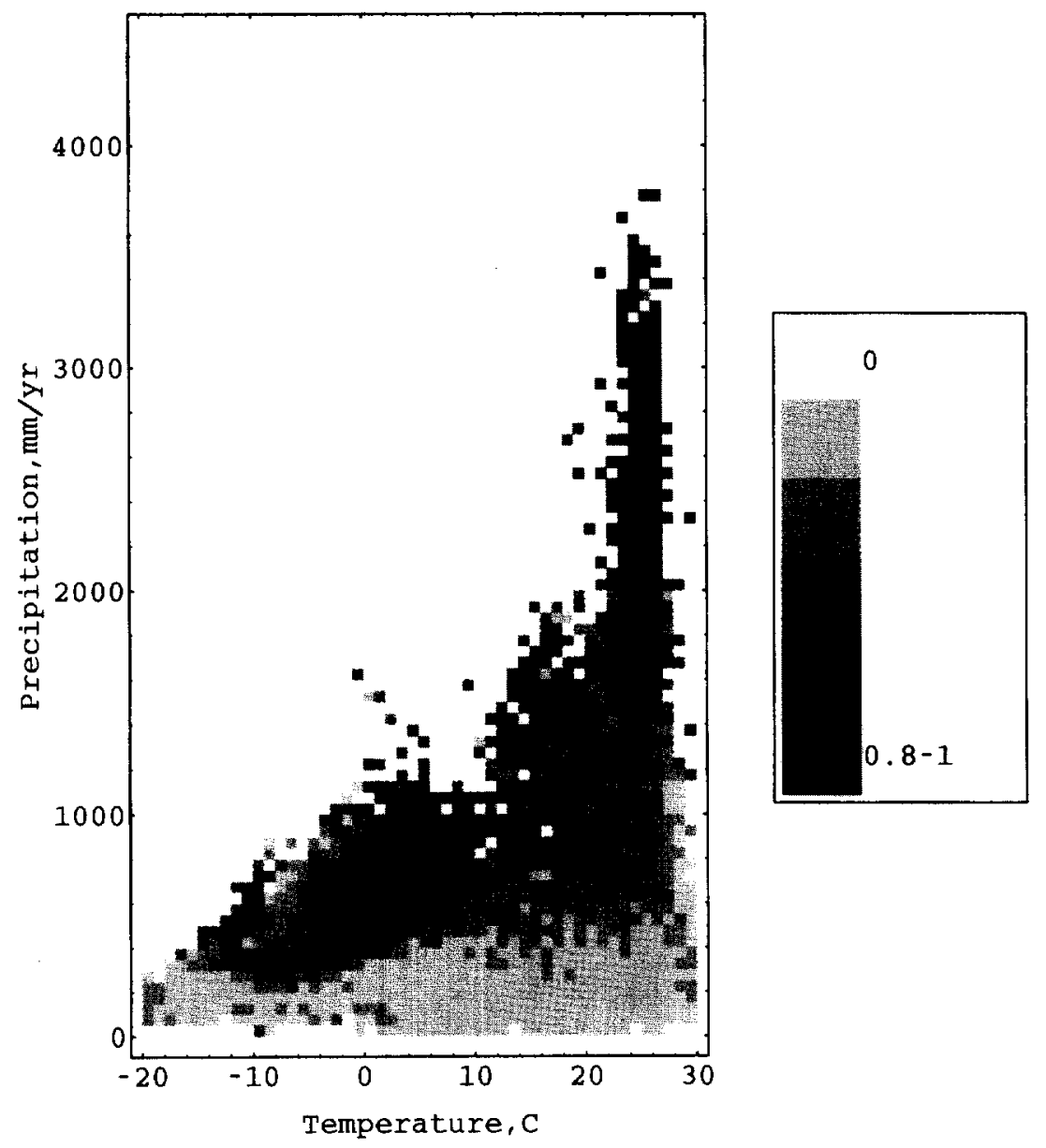

Fig. 1. The trees fraction $f$ as a function of climate. Abscissa, mean annual temperature in Celsius degrees; ordinate, mean annual precipitation in $\mathrm{mm}$. (a) Interpretation of the Olson and Watts' data (1992). (b) Application of Eq. (2).

\subsection{Equation for trees fraction dependence on climate}

The distribution of the trees fraction in climate space (Fig. 1a) was used to design an equation describing the trees fraction $f$ as a function of climate. We approximated this dependence by the following equation:

$f(T, P)=f_{\max } f_{1}(T) \frac{P^{\alpha}}{P^{\alpha}+f_{2}(T)}$

where

$f_{1}(T)=1-e^{-\beta\left(T-T_{\min }\right)}$

$f_{2}(T)=a e^{\gamma\left(T-T_{\min }\right)}$
We used the following assumptions to choose the form of Eq. (2).

- In a cold climate the temperature is the major limiting factor on forest growth.

- In a warm climate the major limiting factor on forest expansion is the annual sum of precipitation.

- Isolines of the trees fraction are corresponded to a constant value of wetness condition.

Let us explain the last assumption in more detail. Main biomes are distinguished in advanced bioclimatic classifications, e.g. in BIOME (Prentice et al., 1992), by thresholds of the ratio of actual and potential transpiration. Obviously, it is impossible to calculate actual and potential tran- 


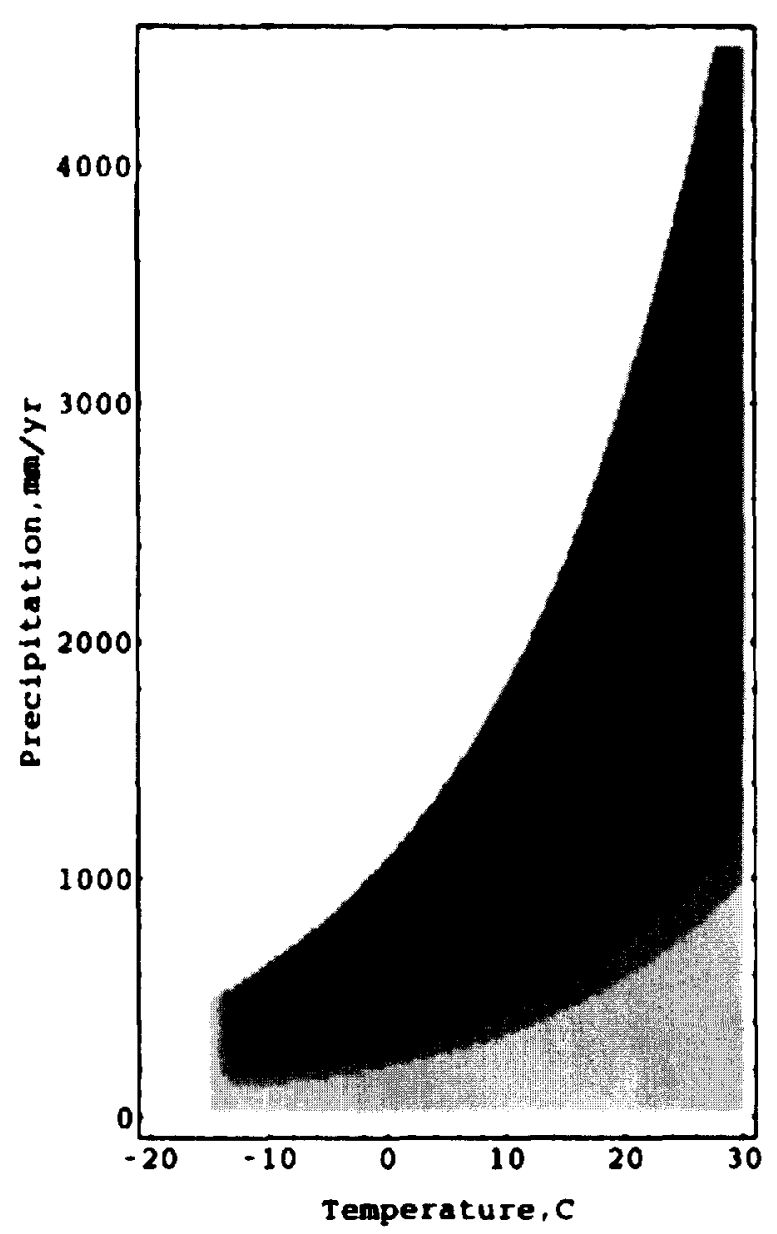

Fig. Ib.

spiration based only on the annual data. Nevertheless, as a first approximation we can assume that for dry warm climate the actual transpiration is proportional to the annual sum of precipitation, and potential transpiration is proportional to air moisture deficit, that in turn is roughly proportional to the specific air humidity for the given temperature. The dependence of specific air humidity on air temperature is described by the Clausis-Clapeyron law (Fleagle and Businger, 1963), which for the limited range of climate conditions could be approximated as $\mathrm{e}^{-\delta \mathrm{T}}$ where $\delta \approx 0.06-0.07$. Therefore we assume that the isolines of the trees fraction correspond to a constant ratio $P / e^{\delta T}$, or

$$
f\left(T, e^{\delta T}\right)=\text { const }
$$

Additional boundary constraints for the trees fraction are

$$
f(T, 0)=0
$$

$f(T, P) \rightarrow f_{\max }$ if $P \rightarrow \infty$

Let us note that the constraint $\left(4^{\prime}\right)$ does not take into account the inhibition of the growth in cold wetlands.

The assumption is also that for fixed temperature $T=T_{0}$ the trees fraction could be described by the relation

$f\left(T_{0}, P\right) \sim P^{\alpha}$ for $P^{\alpha}<f_{2}(T)$ 


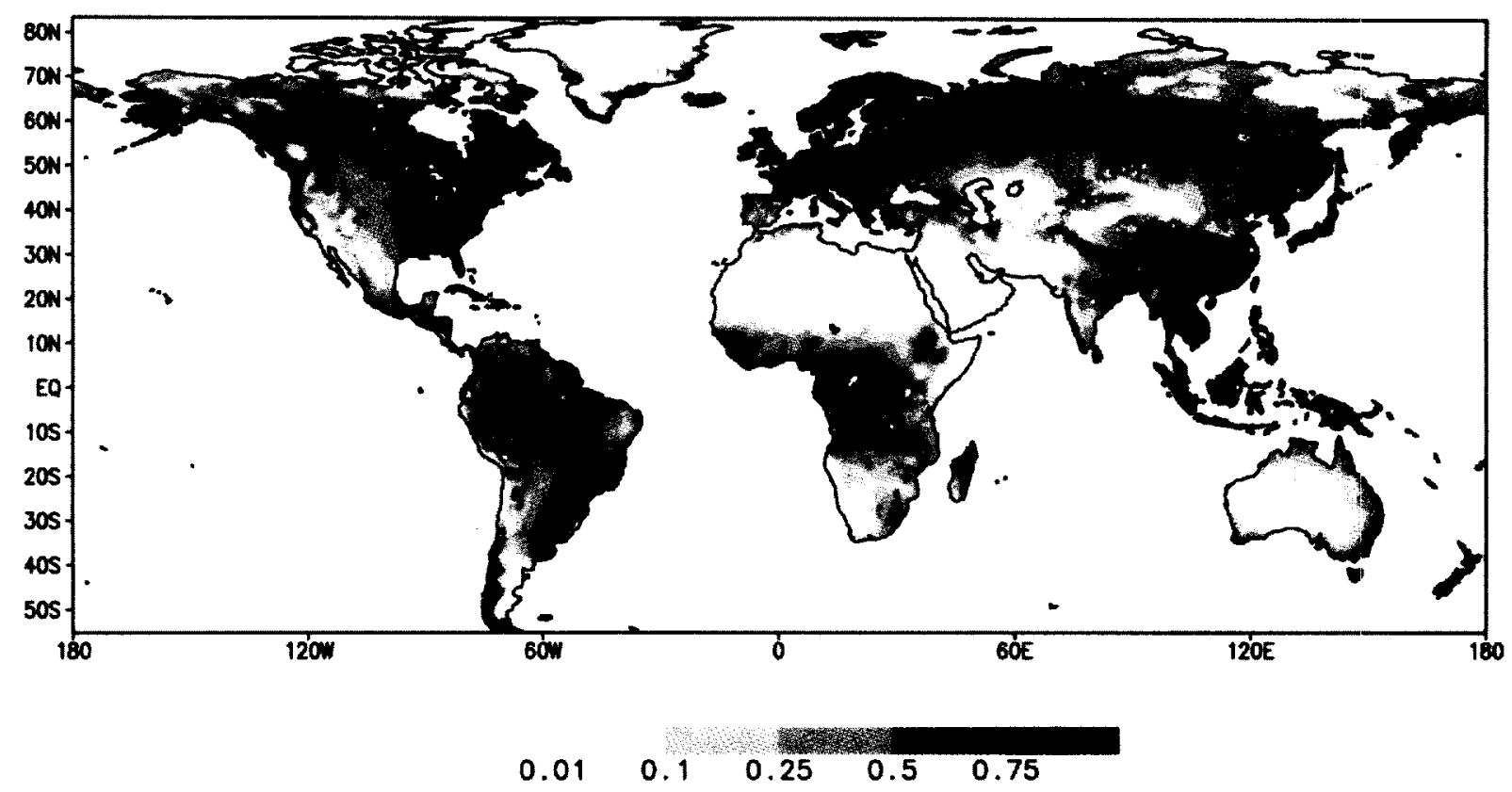

Fig. 2. Geographical distribution of the trees fraction for current climate. Application of Eq. (2).

where $\alpha>1$, since the transition zone between trees and non-trees in climate space is relatively narrow (see Fig. 1a).

Function $f_{1}(T)$ in Eq. (2) reflects a decline of the trees fraction in the vicinity of threshold $T_{\min }$. In accordance with Fig. 1a, $T_{\min }$ was taken as $-15^{\circ} \mathrm{C}$. Trees never occupy a whole cell on a large scale, as some area (e.g. in river valleys or wetlands) is always covered by grass. Therefore the maximum trees fraction $f_{\max }$ was chosen below $1(0.95)$. The value of $\alpha$ was taken equal to 3 . The other parameters in Eq. (2) were tuned to obtain the best correspondence with distribution of the trees fraction in climatic as well as in geographical space. The results were the following: $a=2.6 \times$ $10^{6}, \beta=0.45$ and $\gamma=0.155$.

It is interesting that Eq. (2) is indeed very close to the Clausis-Clayperon law. Assuming $P^{\alpha}<$ $f_{2}(T)$, for a fixed trees fraction we can obtain from Eq. (2) the following link between $T$ and $P$ :

$\frac{P}{e^{\delta\left(T-T_{\min }\right)}} \approx$ Const

where $\delta=\gamma / 3 \approx 0.05$. The nearness of this value to the above-mentioned interval for $\delta=0.06-0.07$ gives some support to our basic assumptions.

\section{Results}

A 2-dimensional image of the calculated trees fraction in the climate space is shown in Fig. $1 b$. For comparison with Fig. 1a, the unobservable high values of precipitation were omitted. As was mentioned above, Eq. (2) cannot reflect all regularities of trees distribution in climate space. For example, in a cold climate with mean temperature below $-5^{\circ} \mathrm{C}$ the relatively high amount of precipitation leads to a decrease of the trees fraction (e.g. in case of northern wetlands). Eq. (2) is too simple to describe this phenomenon. Moreover, climate is not the only factor controling a distribution of vegetation. The impact of other factors, e.g. fire disturbance, could make the grass cover stable, although it is not in equilibrium with climate (Loehle and LeBlanc, 1996). Such cases are outside the scope of our study.

The geographical distribution of $f$ calculated by Eq. (2) for current climate (Leemans and Cramer, 1991) is shown in Fig. 2. Let us emphasise that Eq. (2) was designed for natural vegetation distribution, so large deforested areas of the contemporary Earth are not presented in Fig. 2. Greenland 


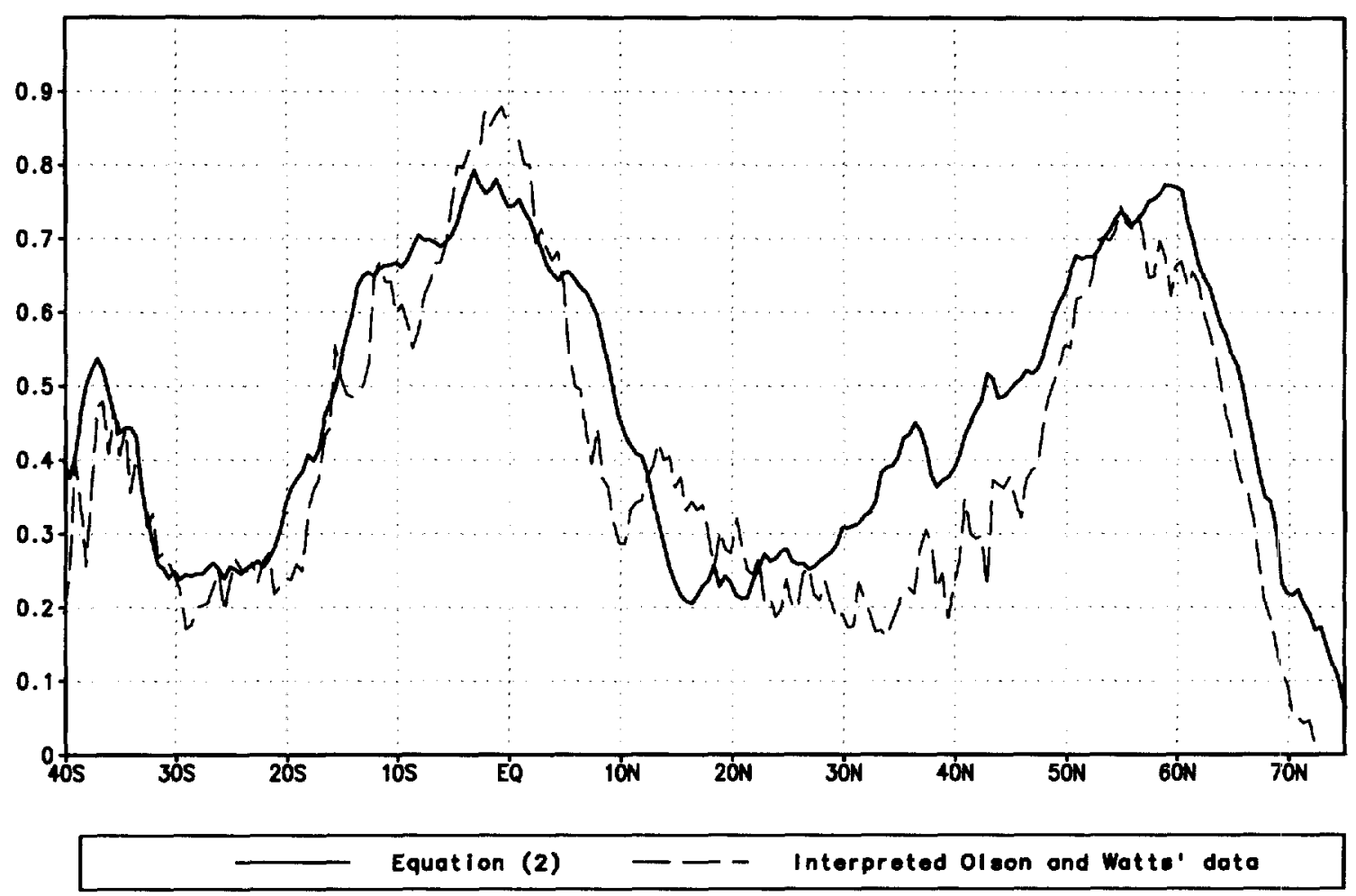

Fig. 3. Comparison of zonally averaged distribution of the trees fraction.

and northern islands, covered mainly by ice, were omitted from consideration. In accordance with Eq. (2), the main trees patterns in the northern hemisphere occur in the eastern part of Northern America, Canada, Europe, Siberia, eastern Asia, China, and South-East Asia. Equatorial areas in South America (Amazon), Africa, and Oceania are mainly covered by trees (except for East Africa). In the southern hemisphere, trees occupy the sub-tropical east coast of the South America, Chile, the south-east coast of Australia and New Zealand. The average fraction of trees for the whole 'natural' Earth equals 0.47 .

In Fig. 2, a value of $f=0.01$ was chosen as a threshold to display of desert areas. Generally, such a threshold represents well enough the boundaries of existing southern deserts. Nevertheless, for a more correct definition of desert it is necessary to include in the classification the parameters of the carbon cycle, e.g. total biomass. The model of the carbon cycle is very important for climate-biosphere studies, but it is outside the scope of our article.

\subsection{Comparison with Olson and Watts' data}

The serious obstacles in validation of Eq. (2) are, firstly, the impact of anthropogenic activity (e.g. deforestation) on natural vegetation distribution, and, secondly, an absence of a global vegetation map based on continuous vegetation description. The several available global maps of natural vegetation, such as Matthews' map (Matthews, 1984), are based on discrete vegetation description. Interpretation of this discrete description in continuous terms is always subjective. Therefore, to avoid additional suggestions, we compared the result of Eq. (2) with the already interpreted data of Olson and Watts for 26 Ecosystem Complexes (see Table 1). For comparison in geographical space, data have been zonally averaged. 


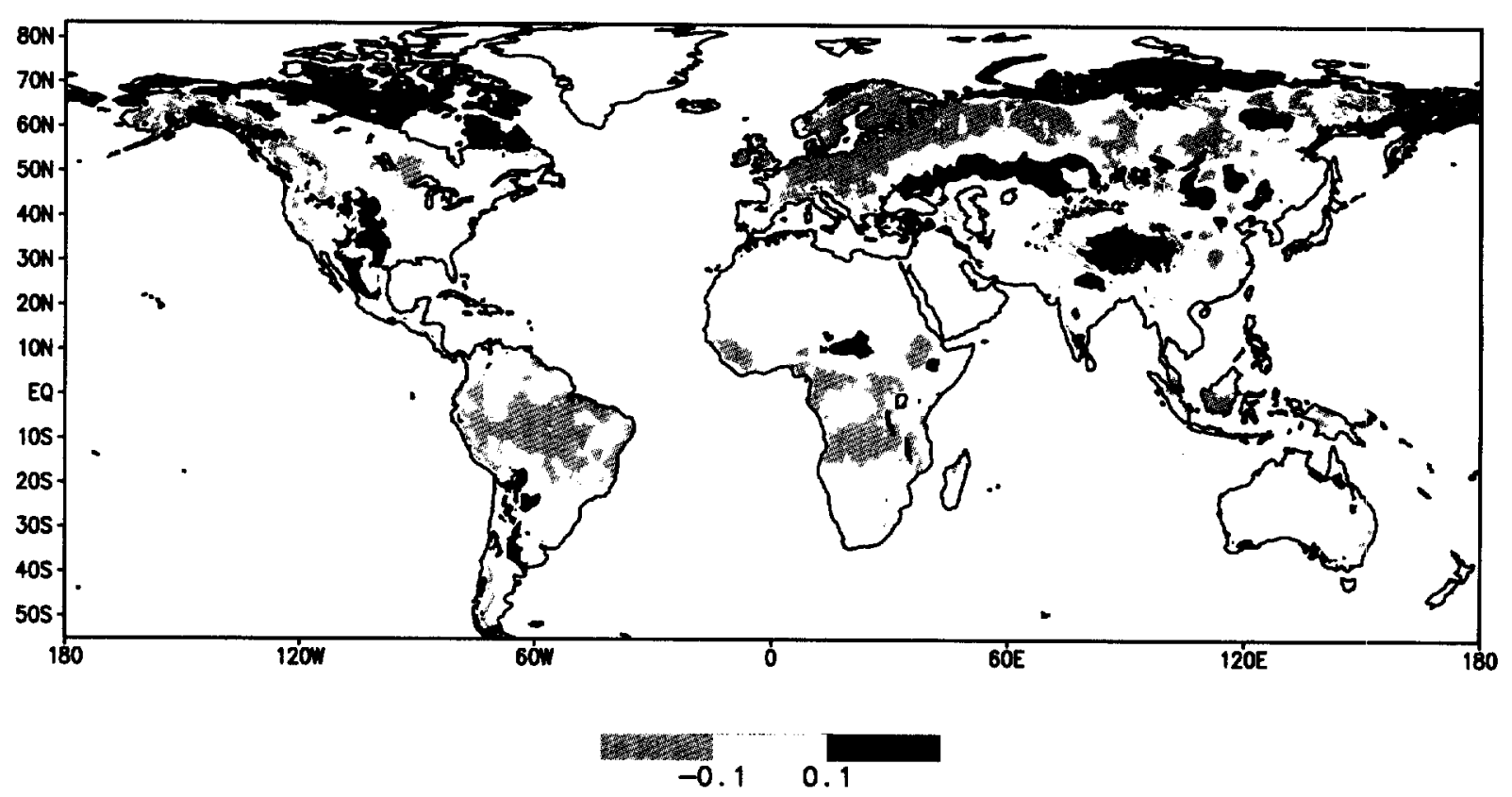

Fig. 4. Change of potential trees fraction for GFDL doubled $\mathrm{CO}_{2}$ climate.

Results of the comparison are presented in Fig. 3. Generally, the main tendencies of trees distribution are fitted well enough: the strong peaks of tropical and boreal forests have been reproduced, as well as drops in the trees fraction in the subtropics. The main inconsistency between the model output and empirical data is in an area between $30^{\circ}$ and $45^{\circ}$ northern latitude. Because of the very strong anthropogenic impact in this area, it is difficult to judge whether this disagreement is caused by a model. Nevertheless, Eq. (2) overestimates the trees fraction in a cold climate, e.g. in the far North, since the mean annual temperature does not reflect a difference in the seasonal temperature amplitude. For example, the same value of $-12^{\circ} \mathrm{C}$ corresponds to the northern taiga growing in the Siberian continental climate, and to northern islands with oceanic climate where the summer is too short and cold for trees growth.

\subsection{Application of Eq. (2) for climate change study}

Climate change leads to shifts in the potential trees fraction. The difference between an applica- tion of $\mathrm{Eq}$. (2) to current climate and to the GFDL double $\mathrm{CO}_{2}$ climate (Houghton et al., 1992) is presented in Fig. 4. To adopt the GFDL climate scenario, we interpolated mean annual climate anomalies to $0.5^{\circ}$ scale grid and added these interpolated values to the Leemans and Cramer's climate data. The strong effect of warming on the trees fraction in the far North is a general result of the application of climate-vegetation classifications to climate change scenarios (Monserud and Leemans, 1992; Monserud et al., 1993; Sykes et al., 1996). The Global Circulation Models (GCMs) predict a stronger warming in high latitudes than in temperate and equatorial zones (Houghton et al., 1996). Therefore the far North, where temperature is a limiting factor on trees growth, is a potential area for forest expansion. Unfortunately, climate-vegetation classifications, representing an equilibrium approach, are useless in providing an answer on how fast successions in transient areas could occur.

In the other areas in Fig. 4, the possible global warming results in a complex picture of change of forest patterns, which in turn reflects a change of two major limiting climatic factors: temperature 
and wetness. Perhaps the increase of the trees fraction in Himalayas area is unrealistic due to model's feature of overestimating the trees fraction in a cold climate. The patterns of the changes of the trees fraction in the temperate and equatorial zones, like the decrease of the trees fraction in Amazonia and Central Europe, are very sensitive to a scenario of climate change.

On a global scale, an average potential fraction of trees declines slightly to 0.45 due to climate change.

\section{Conclusions}

The semi-empirical Eq. (2) simulates the trees fraction dependence on climate parameters. It reflects the main regularities of forest distribution in climatic and geographical spaces. Due to its simplicity, the equation could be easy applied for a diagnostic of the consequences of climate change within climate-biosphere studies.

Let us point out that Eq. (2) is just one example among a wide group of continuous functions satisfying the boundary conditions (Eq. (4)) and other important classification suggestions discussed above. Practically, the only criterion for testing such an equation is a comparison against interpreted global data. If the chosen functions fit this criterion, the differences between their application to climate change studies are minor.

The suggested simple trees-grass vegetation classification is, obviously, very rough. Nevertheless, its simplicity and continuity could be an advantage in comparison with traditional discrete climate-vegetation models in climate-biosphere studies. These classification features are desirable for a proper description of land surface processes in models of the climate system.

\section{Acknowledgements}

We are grateful to Prof. Wolfgang Cramer, Dr Matthias Ludeke and Prof. Martin Claussen for their cordial attention to our research and helpful review comments. UNIX versions of packages MATHEMATICA (Wolfram Research, Inc) and
GrADS (COLA/UMCP) were used for graphical output.

\section{References}

Bartlein, P.J., Prentice, I.C., Webb, T. III, 1986. Climatic response surfaces from pollen data for some eastern North American taxa. J Biogeo 13, 35-57.

Claussen, M., Lohmann U., Roeckner, E., Schulzweida, U., 1994. A Global Data Set of Land-Surface Parameters. Max-Planck-Institut fur Meteorologie, Report No. 135. pp. 23.

Dickinson, R.E., Henderson-Sellers, A., Kennedy, P.J., Wilson, M.F., 1986. Biosphere-Atmosphere Transfer Scheme (BATS) for the NCAR Community Climate Model. NCAR Techn. Note NCAR/TN-275 + STR, pp. 69.

Fleagle, R.G., Businger, J.A., 1963. An introduction to atmospheric physics. Academic Press, New York, pp. 468.

Henderson-Sellers, A., McGuffie, M., 1995. Global climate models and dynamic vegetation changes. Global Change Biol 1, 63-75.

Holdridge, L.R., 1947. Determination of world plant formation from simple climate data. Science $105,367-368$.

Houghton, J.T., Callander, B.A., Varney, S.K., (Eds.), 1992. Climate Change 1992. The Supplementary Report to the IPCC Scientific Assessment. Cambridge University Press, Cambridge.

Houghton, J.T., Meira Filho, L.G., Callander, B.A., (Eds.), 1996. Climate Change 1995: The Science of Climate Change. Cambridge University Press, Cambridge.

Koppen, W., 1936. Das geographische System der Klimate. In: Koppen, W., Geider, R. (Eds.), Handbuch der Klimatologie. Gebruder Borntrager, Berlin, pp. 46.

Leemans, R., Cramer, W.P., 1991. The IIASA database for mean monthly values of temperature, precipitation and cloudiness on a global terrestrial grid. Research Report RR-91-18. International Institute for Applied Systems Analysis, Laxenburg, Austria, pp. 61.

Lenihan, J.M., 1993. Ecological response surfaces for North American boreal tree species and their use in forest classifcation. J Veg Sci 4, 667-680.

Lieth, H., 1975. Modeling the Primary Productivity of the World. In: Lieth, H., Whittaker, R.H., (Eds.), Primary Productivity of the Biosphere. Springer-Verlag, Berlin, 237-263.

Loehle, C., LeBlanc, D., 1996. Model-based assessments of climate change effects on forests: a critical review. Eco Model 90 (1), 1-32.

Ludeke, M., Badeck, F.-W., Otto, R., Hager, C., Donges, S., Kindermann, Ju., Wurth, G., Lang, T., Jakel, U., Klaudius, A., Ramge, P., Habermehl, S., Kohlmaier, G., 1994. The Frankfurt Biosphere Model: a global processoriented model of seasonal and long-term $\mathrm{CO}_{2}$ exchange between terrestrial ecosystems and the atmosphere. I. 
Model description and illustrative results for cold deciduous and boreal forests. Climate Res 4, 143-166.

Matthews, E., 1984. Global vegetation and land use: new high-resolution data base for climate studies. J Climate Appl Meteorol 22 (3), 474-487.

Melillo, J.M., McGuire, A.D., Kicklighter, D.W., Moor, B. III, Vorosmarty, C.J., Schloss, A.L., 1993. Global climate change and terrestrial net primary production. Nature 363 , 234-240.

Monserud, R.A., Leemans, R., 1992. Comparing global vegetation maps with the Kappa statistic. Eco Model 62, 275-293.

Monserud, R.A., Denissenko, O.V., Tchebakova, N.M., 1993. Comparison of Siberian paleovegetation to current and future vegetation under climate change. Climate Res 3, 143-159.

Odum, E.P., 1983. Basic Ecology. CBS College, Philadelphia.
Olson, J., Watts, J.A., 1992. Major World Ecosystem Complexes Ranked by Carbon in Live Vegetation: A Database. NDP-017, Oak Ridge National Laboratory, Oak Ridge, Tennessee, pp. 164.

Prentice, I.C., Cramer, W., Harrison, S.P., Leemans, R., Monserud, R.A., Solomon, A.M., 1992. A global biome model based on plant physiology and dominance, soil properties and climate. J Biogeo 19, 35-57.

Sykes, M.T., Prentice, C.I., Cramer, W., 1996. A bioclimatic model for the potential distribution of north European tree species under present and future climates. J Biogeo 23, 203-233.

Walter, H., 1964. Die Vegetation der Erde in oko-physiologischer Betrachtung. Vol. 1: Die tropischen und subtropischen Zonen. Jena, Fische,. pp. 538.

Walter, H., 1968. Die Vegetation der Erde in oko-physiologischer Betrachtung. Vol. 2: Die gemassigten und arktischen Zonen. Jena, Fischer, pp. 1001. 